\title{
Erratum to: The Impact of Chronic Opioid Use on Colonoscopy Outcomes
}

\author{
Salman Nusrat ${ }^{1,2} \cdot$ Sultan Mahmood $^{1,2} \cdot$ Hussein Bitar $^{1,2} \cdot$ William M. Tierney $^{1,2}$. \\ Klaus Bielefeldt ${ }^{3} \cdot$ Mohammad F. Madhoun $^{1,2}$
}

Published online: 19 May 2015

(C) Springer Science+Business Media New York 2015

\section{Erratum to: Dig Dis Sci (2015) 60:1016-1023 \\ DOI 10.1007/s10620-015-3639-3}

The original version of this article unfortunately contained errors in Table 1 and in the Discussion section.

The values presented in the last four entries in the table are corrected as follows.

\begin{tabular}{lrcc}
\hline & Opioid $n(\%)$ & Non-opioid $n(\%)$ & $P$ value \\
\hline Indication & & & \\
Screening & $41(12.81)$ & $41(13.13)$ & 1.00 \\
FIT-positive & $101(31.56)$ & $97(30.31)$ & 0.79 \\
Symptomatic & $79(24.69)$ & $67(20.94)$ & 0.50 \\
Surveillance & $99(30.94)$ & $114(35.63)$ & 0.24 \\
\hline
\end{tabular}

In the third paragraph of the Discussion section, although the authors did not observe a significant difference in the indications for colonoscopy, patients on chronic opiods had more procedures performed for abdominal pain and changes in bowel habits. A history of depression, chronic pain, and the constipating effects of opioid use likely contributed to these findings.

The online version of the original article can be found under doi:10.1007/s10620-015-3639-3.

Salman Nusrat

salman-nusrat@ouhsc.edu

1 Section of Digestive Diseases, Department of Internal Medicine, University of Oklahoma Health Sciences Center, 920 Stanton Young Blvd. WP 1345, Oklahoma City, OK 73104, USA

2 Veterans Affair Medical Center, Oklahoma City, OK, USA

3 Gastroenterology, Hepatology and Nutrition, University of Pittsburgh Medical Center, 200 Lothrop St, Pittsburgh, PA 15213, USA 